\title{
Comparative analysis of placental vasculature and placental volume in normal and IUGR pregnancies with the use of three-dimensional Power Doppler
}

\author{
Michal Pomorski • Mariusz Zimmer • Jerzy Florjanski • \\ Joanna Michniewicz • Artur Wiatrowski · Tomasz Fuchs • \\ Ewa Milnerowicz-Nabzdyk
}

Received: 13 January 2011/ Accepted: 21 June 2011 / Published online: 9 July 2011

(C) The Author(s) 2011. This article is published with open access at Springerlink.com

\begin{abstract}
Objectives To evaluate the differences in placental vascular indices and placental volume between normal and IUGR pregnancies.

Methods A prospective study was conducted on a group of 100 normal and 20 IUGR pregnancies between 22 and 42 weeks of gestation. For the purpose of evaluation of placental volume and placental vascular indices, we applied 3D Power Doppler and VOCAL technique. Only patients with entirely visualized placenta were included in the study.

Results A comparative analysis of vascularization index (VI), vascularization flow index (VFI), flow index (FI), and placental volume $(\mathrm{PV})$ revealed statistically significant differences between normal and IUGR pregnancies.

In normal pregnancies, the volume of the placenta was on average $92.42 \mathrm{~cm}^{3}$ larger than in pregnancies complicated by IUGR. Receiver operating characteristic (ROC) curves were used to evaluate the clinical usefulness of placental vascular indices and placental volume for discriminating IUGR and normal pregnancies. It was concluded that the VI, VFI, PV, FI parameters are the best discriminants,
\end{abstract}

This study was supported by a research fellowship within the "Development program of Wroclaw Medical University" funded from the European Social Fund, Human Capital Operational Programme, National Cohesion Strategy (contract no. UDAPOKL.04.01.01-00-010/08-01).

M. Pomorski ( $₫)$ M. Zimmer · J. Florjanski · J. Michniewicz ·

A. Wiatrowski - T. Fuchs · E. Milnerowicz-Nabzdyk

Department of Gynecology, Obstetrics and Neonatology,

Wroclaw Medical University, ul. Borowska 213,

50-556 Wroclaw, Poland

e-mail: pomorski.md@gmail.com with the cut-off values of 5.30, 2.30, 199, and 36.0, respectively.

Conclusions The quantitative assessment of placental vasculature and placental volume by means of 3D Power Doppler and VOCAL technique is an adjunctive modality for differentiation between normal and IUGR pregnancies. Our findings further suggest that the vascularization index (VI) and vascularization flow index (VFI) are the best parameters with the most favorable discriminating potential for proper identification of IUGR pregnancies.

Keywords Placenta - Three-dimensional Power Doppler . Vascularization $\cdot$ Fetal growth restriction

\section{Introduction}

Doppler examinations of intraplacental blood circulation appear to be an efficient method for diagnosing and managing pregnancies complicated by fetal intrauterine growth restriction (IUGR), especially because the changes in maternal Doppler findings (i.e., uterine artery) and in fetal Doppler (i.e., umbilical artery) are secondary to the changes in the placental vascular tree [1-3].

Thanks to great technological progress over the last few years, it is now possible to quantitatively evaluate intraplacental blood circulation and placental volume by means of 3D Power Doppler and VOCAL technique. Intraplacental blood circulation is described by three vascular indices: vascularization index (VI), flow index (FI), and vascularization flow index (VFI). Vascularization index is the ratio of the number of color voxels to the total number of voxels in the sampled tissue, thus it represents the percentage of vascularized tissue [4-7]. Flow index is the average color value of all color voxels and it describes the 
Table 1 Comparative characteristics of the selected normal pregnancies subgroup and the IUGR pregnancies group

\begin{tabular}{llll}
\hline Variable & $\begin{array}{l}\text { Normal } \\
\text { pregnancies group } \\
(n=55)\end{array}$ & $\begin{array}{l}\text { IUGR } \\
\text { pregnancies group } \\
(n=20)\end{array}$ & $p$ value \\
\hline Age $^{\mathrm{a}}$ & $30.8 \pm 5.7$ & $31.3 \pm 4.8$ & 0.28 \\
$\begin{array}{l}\text { Parity } \\
(\text { primapara/ } \\
\text { multipara) }\end{array}$ & $32(58 \%) / 23(42 \%)$ & $12(60 \%) / 8(40 \%)$ & 0.89 \\
$\begin{array}{l}\text { Gestational age } \\
\text { (median, } \\
\text { range) }\end{array}$ & $35.00(31.0-41.0)$ & $33.50(29.0-40.0)$ & 0.43 \\
\hline
\end{tabular}

${ }^{a}$ Average \pm standard deviation (SD), $p$ value calculated by means of the Student's $t$ test for independent variables

${ }^{\mathrm{b}} p$ value calculated by means of the Chi-square test

c Median (range), $p$ value calculated by means of the Mann-Whitney $U$ test

mean velocity of flow in the sampled tissue [4-7]. The vascularization-flow index is the average color value of all color and gray voxels and describes both: the vascularization and the blood flow $[6,7]$.

So far, only a small number of studies evaluating placental vasculature with the use of 3D Power Doppler technique have been conducted [4-8]. They differed from one another in respect of the applied methodologies of measuring the placental vasculature. Until recently, placental vasculature was evaluated only in selected parts of the placenta [5-8]. However, not unlike in the study performed by de Paula et al. [4], we applied a method allowing for measuring vascular indices for the entire placental volume. This allowed us to gather full information on placental vasculature and should not be underestimated as, due to high regional variability of placental perfusion, there are significant differences in the values of vascularization index, flow index, and vascularization-flow index between different regions of the placenta $[9,10]$.
Moreover, no study comparing placental vascular indices of the whole placental volume in normal and IUGR pregnancies has been found.

The quantitative assessment of the vasculature of the entire placenta aims both the evaluation of potential differences of placental vascular indices and placental volume found in normal and IUGR pregnancies. Secondarily, we tried to demonstrate whether the assessment of these parameters might be useful as an adjunctive method in discriminating normal from IUGR pregnancies.

\section{Materials and methods}

A prospective study included 120 pregnant patients who underwent ultrasound examinations within the period from September 2008 to November 2009, carried out in the Department of Gynecology, Obstetrics and Neonatology, Wroclaw Medical University. All patients gave informed consent for participation in the study and the local ethics committee accepted the protocol of the study.

The normal pregnancy group included 100 patients between 22 and 42 weeks of gestation (mean gestational age, 32.0 weeks). The IUGR pregnancy group included 20 patients between 29 and 40 weeks of gestation (mean gestational age, 33.5 weeks). We found statistically significant differences in gestational age between the two groups of pregnancies $(p=0.006)$. Therefore, in order to compare the two groups, we separated a subgroup out of the normal pregnancies group. The subgroup included 55 patients over 29 weeks of gestation. Table 1 presents comparative characteristics of the selected normal pregnancy subgroup and the IUGR pregnancy group.

The inclusion and exclusion criteria are presented in Table 2 .

In order to avoid including healthy, yet constitutionally small for gestational age fetuses to the IUGR group, patients' data were included in the study only in cases of IUGR diagnosis confirmed after delivery.

Table 2 Inclusion/exclusion criteria of the normal and IUGR subgroups

\begin{tabular}{|c|c|c|}
\hline & Inclusion criteria & Exclusion criteria \\
\hline $\begin{array}{l}\text { Normal } \\
\text { pregnancies } \\
\text { group }\end{array}$ & $\begin{array}{l}\text { Singleton pregnancy, lack of systemic disease, normal fetal } \\
\text { morphology, fetal growth appropriate for gestational age, } \\
\text { gestational age above the } 22 \text { nd week, visualization of the } \\
\text { entire placenta }\end{array}$ & $\begin{array}{l}\text { Multiple pregnancy, systemic disease, incorrect fetal NT value } \\
\text { between the 11th and the 13,6th weeks of gestation, } \\
\text { abnormal fetal karyotype, fetal malformations, fetal growth } \\
\text { inappropriate for gestational age, gestational age under the } \\
\text { 22nd week abnormal localization of the placenta, inability to } \\
\text { visualize the entire placenta drug, alcohol, nicotine abuse }\end{array}$ \\
\hline $\begin{array}{l}\text { IUGR } \\
\text { pregnancies } \\
\text { group }\end{array}$ & $\begin{array}{l}\text { Singleton pregnancy, estimated fetal weight below the } 10 \text { th } \\
\text { percentile for gestational age, gestational age above the } 22 \text { nd } \\
\text { week, the diagnosis of IUGR confirmed after delivery }\end{array}$ & $\begin{array}{l}\text { Multiple pregnancy, unknown date of delivery, estimated fetal } \\
\text { weight above the 10th percentile for a given gestational age, } \\
\text { diagnosis of IUGR not confirmed after the delivery, inability } \\
\text { to visualize the entire placenta }\end{array}$ \\
\hline
\end{tabular}


Maternal characteristics of the IUGR group included nicotine abuse during the pregnancy in four cases $(4 / 20)$, history of recurrent abortion in one case $(1 / 20)$ and pregnancy inducted hypertension in one case (1/20). Other systemic diseases or prior uterine surgeries were not found in this group of patients.

\section{Methods of ultrasound examination}

Ultrasound examinations were performed using Voluson E8 Expert (General Electric Medical Systems) with a volumetric abdominal probe RAB 4-8D (4-8 MHz).

We applied the following procedures for each case:2D ultrasound scanning evaluating fetal biometric parameters according to Hadlock et al. [11], fetal morphology, and localization of the placenta, evaluation of placental volume (PV) and placental vascular indices (VI, VFI, FI) with the use of 3D Power Doppler and VOCAL technique.

Ultrasound examinations were performed by a single operator (M.P.).

Assessment of placental volume and placental vascular indices

In order to standardize our evaluation of placental vasculature, the same pre-established Power Doppler signal settings were used for the following parameters: pulse repetition frequency: $0.9 \mathrm{kHz}$, wall motion filter: low1, quality: norm, frequency: low, smooth: $4 / 5$, artefact on.

A gain value was set individually, depending on the location of placenta, the thickness of maternal adipose tissue and imaging conditions resulting from these factors. At the beginning of a 3D Power Doppler examination, the maximum gain value was set to be later reduced to such a level that would eliminate any artifacts and allow us to obtain a proper image of the placental vascular tree. We benefited from the fact that individual adjustment of Power Doppler signal level allows for adequate and comparable assessment of placental vasculature, and there is no need to maintain a constant distance between a probe and the placenta, which in practice is impossible [12]. As recommended by Martins et al. [13], in this study, we applied the lowest gain settings allowing for adequate detection of vessel architecture.

After visualization of the placental vascular tree, we performed a 3D static Power Doppler scanning using the widest scanning angle $\left(85^{\circ}\right)$ to ensure that the data from the entire placenta is collected. Having scanned the region of interest, we used VOCAL II imaging software to assess placental volume (VOCAL settings: manual trace, rotation angle $30^{\circ}$ ). Further analysis was performed with the use of 3D Power Doppler Volume Histogram software, which automatically calculates the values of VI, FI, and VFI for the entire placental volume.

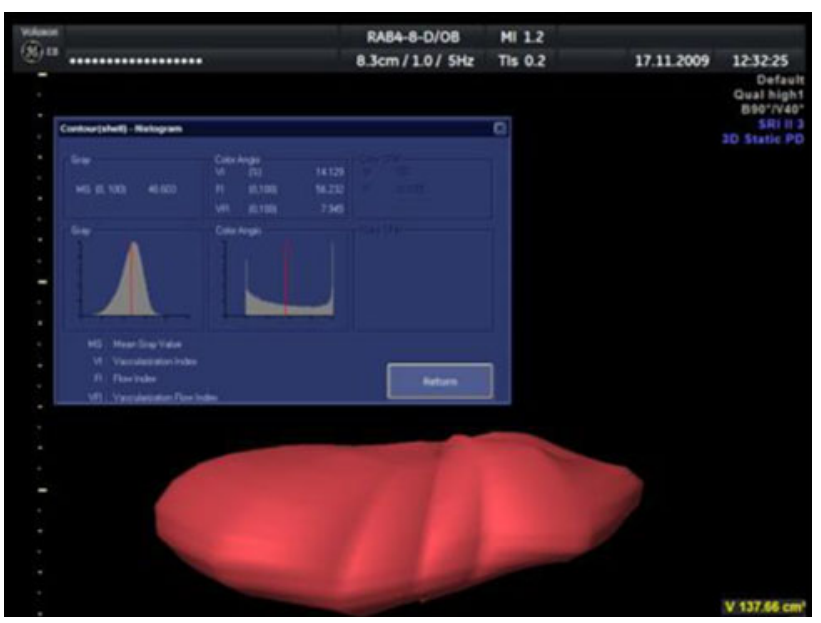

Fig. 1 Automatic calculation of VI, FI and VFI by 3D-Power Doppler Volume Histogram program

Figure 1 presents the above-mentioned technique of measuring placental volume and placental vasculature.

Statistical analysis

Statistical analysis was performed with STATISTICA 9.0 software (StatSoft Inc., Poland). A $p$ value of less than 0.05 was considered statistically significant.

Receiver operating characteristic (ROC) curves were applied in order to evaluate the use of PV, VI, FI, and VFI indices in discriminating between normal and IUGR pregnancies. We calculated the areas under the ROC curve (AROC) values, 95\% confidence Wald intervals for AROC values, and the cut-off (CUT) value. Furthermore, the specificities for target sensitivity of at least $80 \%$ were calculated and compared for each parameter.

\section{Results}

Comparison of placental vascular indices in normal and IUGR pregnancies

Table 3 presents the results of comparative analyses of placental vascular indices in normal and IUGR pregnancies.

A comparative analysis of VI revealed a statistically significant difference $(p<0.001)$ between the normal pregnancy subgroup (median value 13.7) and the IUGR pregnancy group (median value 5.7); further analysis also showed a statistically significant difference of FI $(p=$ 0.002 ) between the normal pregnancy subgroup (46.55 \pm $6.48)$ and the IUGR pregnancy group (40.93 \pm 7.25$)$. On average, in the normal pregnancies subgroup FI was higher 
Table 3 Comparative analysis of placental vascular indices in normal and IUGR pregnancies

\begin{tabular}{lllr}
\hline Variable & $\begin{array}{l}\text { Normal pregnancies } \\
\text { group }(n=55)\end{array}$ & $\begin{array}{l}\text { IUGR pregnancies } \\
\text { group }(n=20)\end{array}$ & $p$ value \\
\hline $\mathrm{VI}^{\mathrm{a}}$ & $13.7(3.80-33.0)$ & $5.75(0.60-14.50)$ & $<0.001$ \\
$\mathrm{FI}^{\mathrm{b}}$ & $46.55 \pm 6.48$ & $40.93 \pm 7.25$ & 0.002 \\
$\mathrm{VFI}^{\mathrm{a}}$ & $6.0(1.30-15.0)$ & $2.25(0.30-7.70)$ & $<0.001$
\end{tabular}

$V I$ vascularization index, $F I$ flow index, VFI vascularization-flow index

${ }^{a}$ Median (range of values), $p$ value calculated by means of the Mann-Whitney $U$ test

b Average \pm standard deviation (SD), $p$ value calculated by means of the Student's $t$ test for independent variables

by 5.62 than in the IUGR pregnancies group. A comparative analysis of VFI concluded that there is a statistically significant difference $(p<0.001)$ between the normal pregnancies subgroup (median value 6.0 ) and the IUGR pregnancies group (median value 2.25 ).

Comparison of placental volume in normal and IUGR pregnancies

A comparative analysis of placental volume between the normal pregnancies subgroup and IUGR pregnancies group (Table 1) revealed a statistically significant difference. The mean volume in the normal pregnancies subgroup and IUGR pregnancies group was $334.87 \pm 89.06$ and $242.45 \pm 67.15 \mathrm{~cm}^{3}$, respectively. In the normal pregnancies subgroup, the volume of placenta was on average $92.42 \mathrm{~cm}^{3}$ larger than in the IUGR pregnancies group.

Figure 2 presents a comparison of placental volume between the normal pregnancies subgroup and the IUGR pregnancies group.

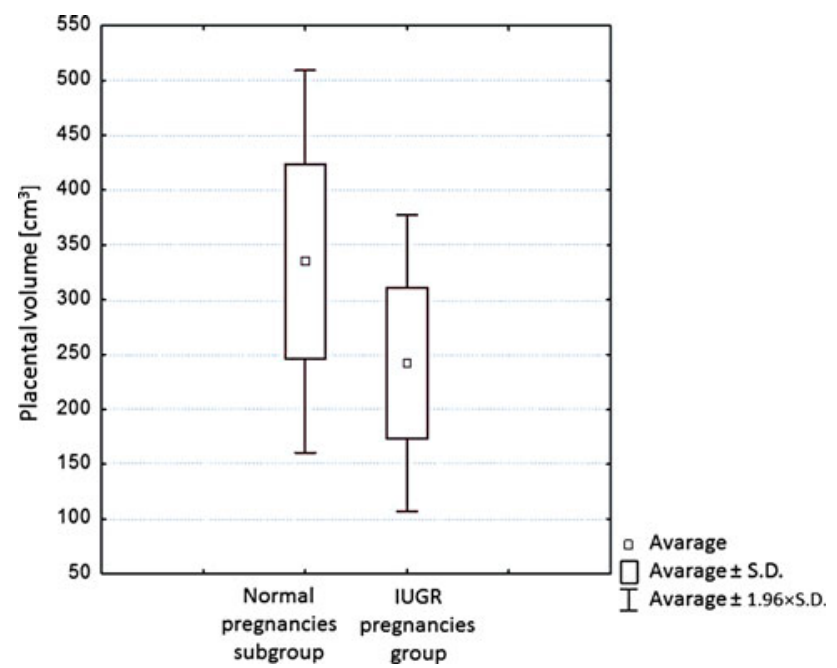

Fig. 2 Comparison of placental volume in normal and IUGR pregnancies
Evaluation of clinical usefulness of placental volume and placental vascular indices for discriminating between IUGR and normal pregnancies

Results of an analysis where ROC curves were used for vascularization index, flow index, vascularization flow index and placental volume were presented in Table 3.

Table 4 presents placental vascular indices and placental volume parameters. These parameters were presented in descending order as regards the area under ROC curve (AROC).

The following parameters showed the highest AROC values, respectively:

- vascularization index VI

- vascularization flow index VFI

- placental volume PV

- flow index FI.

Sensitivity to the best three parameters (VI, VFI, PV) for specificity of $80 \%$ ranged between 60 and $70 \%$. The CUT values for VI, VFI, PV, and FI were 5.30, 2.30, 199, and 36.0 , respectively.

Figure 3 presents collective comparison of the ROC curves for VI, VFI, FI, and PV indices.

\section{Discussion}

Methods used for evaluation of placental vasculature and placental volume

In the study conducted by Yu et al. [8] in 2003 the values of placental vascular indices VI, FI, and VFI were calculated for a fixed, small placental volume. Mercé et al. [6,7] further developed this technique and called it "vascular placental biopsy"; it consists of scanning a part of the placenta with the highest density of vessels.

In yet another study by Guiot et al. [5], the values of placental vascular indices were determined in five constant regions of the placenta.

Furthermore, in 2009, de Paula et al. [4], introduced the method of measuring the vascular indices for the entire placental volume. This method revealed that the values of VI, FI, and VFI remain constant during the entire pregnancy. Thus, these results differ from those presented by $\mathrm{Yu}$ et al., and Mercé et al. [6-8], which concluded that the values of VI, FI, and VFI increase during the course of pregnancy.

This study, allowing for gathering full information on placental vasculature, utilized a method measuring VI, FI, and VFI in the entire placental volume. It is especially important in IUGR pregnancies, where vasculature structure is much more differentiated due to the presence of villous infarcts [5, 14, 15]. Recently, Lai et al., and Negrini 
Table 4 Comparative table of areas under ROC curve values for vascular indices VI, FI, VFI and placental volume PV; their sensitivities values for specificity of $80 \%$ and CUT values

\begin{tabular}{|c|c|c|c|c|c|c|}
\hline & AROC & SE & $-95 \%$ & $+95 \%$ & CUT & $\begin{array}{l}\text { Sensitivity } \\
\text { for specificity } \\
\text { of } 80 \%(\%)\end{array}$ \\
\hline VI & 0.825 & 0.052 & 0.724 & 0.927 & 5.30 & 65.0 \\
\hline VFI & 0.818 & 0.059 & 0.702 & 0.934 & 2.30 & 70.0 \\
\hline $\mathrm{PV}\left(\mathrm{cm}^{3}\right)$ & 0.795 & 0.055 & 0.687 & 0.903 & 199 & 60.0 \\
\hline FI & 0.712 & 0.068 & 0.579 & 0.844 & 36.0 & 40.0 \\
\hline
\end{tabular}

$-95 \%$ left confidence interval, $+95 \%$ right confidence interval are adjusted Wald confidence interval, AROC area under the ROC curve, SE standard error, $V I$ vascularization index, $F I$ flow index, $V F I$ vascularization-flow index, $P V$ placental volume, $C U T$ cut point of the ROC curve

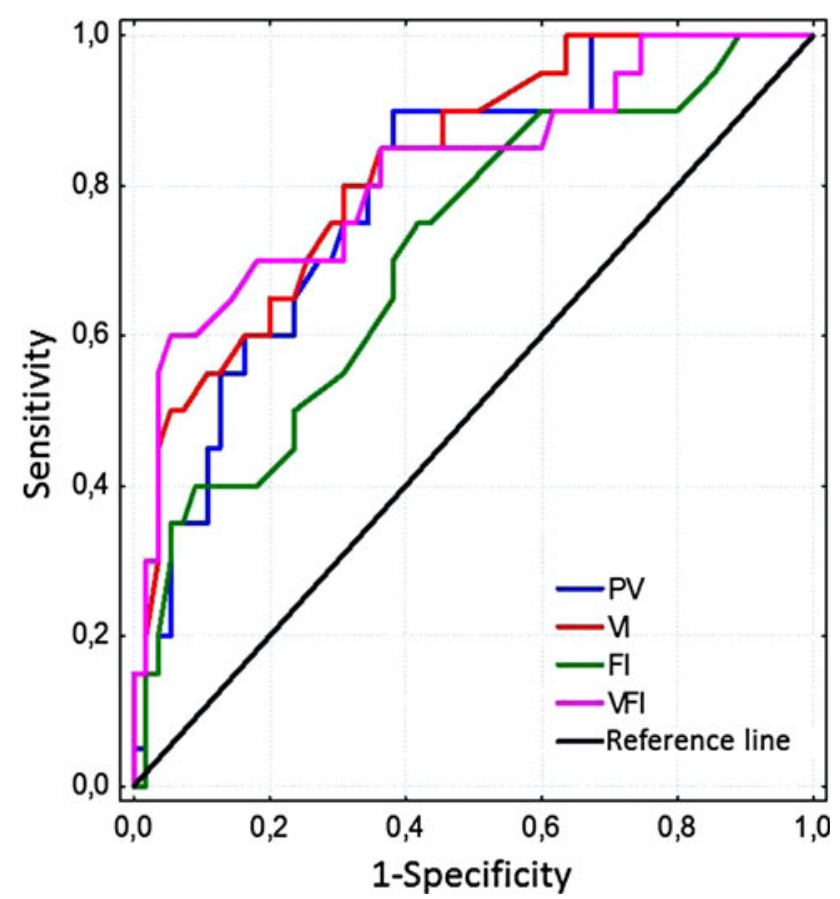

Fig. 3 Comparison of the ROC curves for VI, FI, VFI and PV indices in the IUGR pregnancies group

et al. [9, 10], have also concluded that even in normal pregnancies, significant differences between the values of placental vascular indices (VI, FI, VFI) obtained from different regions of the placenta can be found. Furthermore, this method might help to get valuable information on placental volume, which may be used as an independent diagnostic parameter differentiating between properly and insufficiently developed placentas. However, only patients with proper visualization of the entire placenta are eligible for this method.

Comparative analysis of placental vasculature in normal and IUGR pregnancies

So far, the only study to compare placental vasculature in normal pregnancy to placental vasculature in IUGR pregnancy by means of 3D Power Doppler and VOCAL technique has been the study by Guiot et al. [5]. The study was performed on a group of 45 pregnant women between 23 and 37 weeks of gestation, including 30 IUGR and 15 normal pregnancies. Placental vascular indices were calculated for five different regions of the placenta. The authors stated that VI, FI, and VFI values were significantly lower in the IUGR pregnancies [5].

In the present study, placental vasculature in normal and IUGR pregnancies were compared, while all measures were derived from the entire placental volume by using 3D Power Doppler technique.

Based on our findings, we were able to show that the values of VI, FI, and VFI are statistically significantly lower in the IUGR group compared to those in the normal group. Our results clearly show that placentas of IUGR complicated pregnancies have fewer blood vessels (reduced VI) and decreased blood flow (reduced FI) as well.

The data presented herein correlate with the results of histopathological and 2D Doppler studies [16, 17]. A major advantage of 3D Power Doppler technique, in comparison to the above-mentioned techniques, is the possibility of quantitative evaluation of placental vascular indices for the entire placental volume during the pregnancy.

Comparative analysis of placental volume in normal and IUGR pregnancies

In 2008, de Paula et al. [18], established reference values for placental volume between the 12th and 40th week of gestation, with the use of three-dimensional ultrasonography.

Hafner et al. [19], revealed that measurement of placental volume between 16 and 23 weeks' gestation has a sensitivity of $53.5 \%$ regarding the prediction of IUGR and neonatal birth weight below the 10th percentile. Later on the group of Hafner stated that measurement of placental volume in the first and the second trimester of pregnancy enables identification of impaired trophoblast invasion and helps predict the development of IUGR and preeclampsia [20, 21]. 
Our study sought to elaborate whether placental volume measured by means of VOCAL technique may serve as a parameter differentiating between normal and IUGR pregnancies. The performed comparative analyses revealed statistically important differences of placental volume between the normal pregnancy and the IUGR pregnancy groups. Our findings show that the placentas in IUGR pregnancies are on average smaller by $92.66 \mathrm{~cm}^{3}$ in comparison to the placentas in normal pregnancies.

Clinical usefulness of placental vasculature indices and placental volume for discriminating between normal and IUGR pregnancies

To the best of our knowledge, no previous studies using ROC curves to evaluate clinical usefulness of placental vascular indices and placental volume for discriminating between normal and IUGR pregnancies have been published so far. We obtained the highest AROC values for vascularization index VI, vascularization flow index VFI, and placental volume PV, differentiating between normal and IUGR pregnancies. These findings might suggest that placentas of IUGR pregnancies presumably contain fewer blood vessels (lower VI and VFI value) and have reduced volume (lower PV value). The flow index, which equals the average placental blood flow volume, seems to be affected less significantly and is not useful for differentiating between normal and IUGR pregnancies. These data are similar to the results presented by Guiot et al. [5], who showed that the lower FI value is diagnosed only in the most severe cases of IUGR, i.e., in the cases of AEDV or REDV in the umbilical artery.

Potential limitations of the study

Future studies are needed to assess the correlation between the vascularization of placenta and changes in maternal and fetal Doppler findings. Due to the fact that these changes are secondary to the impaired development of the placental vascular tree, the placental vascular indices may be used for early detection of pregnancies with the high risk of fetal intrauterine growth restriction.

The method of assessment of the vascular tree in the entire placental volume requires the exclusion of patients where the scanning of the entire placenta is not possible. This mostly concerns patients with obesity and patients in advanced pregnancy.

\section{Conclusions}

To summarize, the quantitative assessment of placental vasculature and placental volume by means of 3D Power
Doppler and VOCAL technique is an adjunctive modality for differentiation between normal and IUGR pregnancies. Our findings further suggest that the vascularization index (VI) and vascularization flow index (VFI) are the best parameters with the most favorable discriminating potential for proper identification of IUGR pregnancies.

Conflict of interest The authors declare that they have no conflict of interest.

Open Access This article is distributed under the terms of the Creative Commons Attribution Noncommercial License which permits any noncommercial use, distribution, and reproduction in any medium, provided the original author(s) and source are credited.

\section{References}

1. Abramowicz JS, Sheiner E (2007) In utero imaging of the placenta: importance for diseases of pregnancy. Placenta 28(Suppl A): 14-22

2. Abramowicz JS, Sheiner E (2008) Ultrasound of the placenta: a systematic approach. Part I: imaging. Placenta 29:225-240

3. Abramowicz JS, Sheiner E (2008) Ultrasound of the placenta: a systematic approach. Part II: functional assessment (Doppler). Placenta 29:921-929

4. de Paula CF, Ruano R, Campos JA, Zugaib M (2009) Quantitative analysis of placental vasculature by three-dimensional Power Doppler ultrasonography in normal pregnancies from 12 to 40 weeks of gestation. Placenta 30:142-148

5. Guiot C, Gaglioti P, Oberto M, Piccoli E, Rosato R, Todros T (2008) Is three-dimensional Power Doppler ultrasound useful in the assessment of placental perfusion in normal and growthrestricted pregnancies? Ultrasound Obstet Gynecol 31(2): $171-176$

6. Mercé LT, Barco MJ, Bau S, Kupesic S, Kurjak A (2005) Assessment of placental vascularization by three-dimensional Power Doppler "vascular biopsy" in normal pregnancies. Croat Med J 46:765-771

7. Mercé LT, Barco MJ, Bau S (2004) Reproducibility of the study of placental vascularization by three-dimensional Power Doppler. J Perinat Med 32:228-233

8. Yu CH, Chang $\mathrm{CH}$, Ko HC, Chen WC, Chang FM (2003) Assessment of placental fraction moving blood volume using quantitative three-dimensional Power Doppler ultrasound. Ultrasound Med Biol 29:19-23

9. Lai PK, Wang YA, Welsh AW (2010) Reproducibility of regional placental vascularity/perfusion measurement using 3D Power Doppler. Ultrasound Obstet Gynecol 36:202-209

10. Negrini R, de Silva Bussamra LC, da Silva Valladão de Freitas L, Araujo Júnior E, Piato S, Nardozza LM, Moron AF, Aoki T (2010) Assessment of placental blood flow between 22 and 34 weeks of gestation by 3D-sonography Power Doppler vascular indices. Arch Gynecol Obstet 284:53-57

11. Hadlock FP, Harrist RB, Sharman RS, Deter RL, Park SK (1985) Estimation of fetal weight with the use of head, body and femur measurements-a prospective study. Am J Obstet Gynecol 151:333-337

12. Pomorski M (2010) Assessment of placental vascularisation in normal and complicated pregnancies with the use of Power Doppler ultrasonography. Dissertation. Wroclaw Medical University 
13. Martins WP, Raine-Fenning NJ, Ferriani RA, Nastri CO (2010) Quantitative three-dimensional Power Doppler angiography: a flow-free phantom experiment to evaluate the relationship between color gain, depth and signal artifact. Ultrasound Obstet Gynecol 35:361-368

14. Madazli R, Somunkiran A, Calay Z, Ilvan S, Aksu MF (2003) Histomorphology of the placenta and the placental bed of growth restricted foetuses and correlation with the Doppler velocimetries of the uterine and umbilical arteries. Placenta 24:510-516

15. Vedmedovska N, Rezeberga D, Teibe U, Melderis I, Donders GG (2010) Microscopic lesions of placenta and Doppler velocimetry related to fetal growth restriction. Arch Gynecol Obstet. doi: 10.1007/s00404-010-1781-x

16. Mitra SC, Seshan SV, Riachi LE (2000) Placental vessel morphometry in growth retardation and increased resistance of the umbilical artery Doppler flow. J Matern Fetal Med 9:282-286

17. Mu J, Kanzaki T, Tomimatsu T, Fukuda H, Fujii E, Takeuchi H et al (2002) Investigation of intraplacental villous arteries by
Doppler flow imaging in growth-restricted fetuses. Am J Obstet Gynecol 186:297-302

18. de Paula CF, Ruano R, Campos JA, Zugaib M (2008) Placental volumes measured by 3-dimensional ultrasonography in normal pregnancies from 12 to 40 weeks' gestation. J Ultrasound Med 27:1583-1590

19. Hafner E, Philipp T, Schuchter K, DiIlinger-Paller B, Philipp K, Bauer P (1998) Second-trimester measurement of placental volume by three-dimensional ultrasound to predict small-for-gestational-age infants. Ultrasound Obstet Gynecol 12:97-102

20. Hafner E, Metzenbauer M, Dillinger-Paller B, Hoefinger D, Schuchter K, Sommer-Wagner H et al (2001) Correlation of first trimester placental volume and second trimester uterine artery Doppler flow. Placenta 22:729-734

21. Hafner E, Metzenbauer M, Hoefinger D, Munkel M, Gassner R, Schuchter K et al (2003) Placental growth from the first to the second trimester of pregnancy in SGA-foetuses and pre-eclamptic pregnancies compared to normal fetuses. Placenta 24:336-342 